\title{
Factors Affecting Nurses' Compliance in Preventing Pressure Ulcer Among Hospitalized Patients at King Abdulaziz University Hospital
}

\author{
Arwa Al-Ghamdi \\ Specialized Nurse \& Coordinator of Pediatric Cardiac Surgery, Pediatric Cardiac Surgery Department, King Abdulaziz University Hospital, \\ Jeddah, KSA \\ Email address: \\ cardiac_kau@yahoo.com

\section{To cite this article:} \\ Arwa Al-Ghamdi. Factors Affecting Nurses' Compliance in Preventing Pressure Ulcer Among Hospitalized Patients at King Abdulaziz \\ University Hospital. American Journal of Nursing Science. Vol. 6, No. 5, 2017, pp. 387-395. doi: 10.11648/j.ajns.20170605.13
}

Received: July 26, 2017; Accepted: August 31, 2017; Published: September 25, 2017

\begin{abstract}
Prevention of pressure ulcers is an indicator of quality of care. Nursing care has a major effect on pressure ulcer development and prevention. Hence, many people believe that most pressure ulcers are preventable if the appropriate interventions are implemented. The study aimed to assess factors affecting nursing compliance in preventing pressure ulcer. Descriptive correlation design was used which is a type of non-experimental design to collect data from medical, surgical units and the critical cardiac unit at King Abdulaziz University Hospital in Jeddah city. Purposive sampling technique was carried out to select 113 nurses and 113 patients. Data were collected by three tools, tool 1 is a structured questionnaire divided into 2 parts, included demographic data and list of barriers facing nurses in preventing pressure ulcer, tool 2 is an observational checklist and tool 3 is the Waterlow pressure ulcer risk assessment tool. The study concluded that there is significant correlation between barriers and nursing compliance in prevention pressure ulcer. Heavy workload/staff shortage is considered as the most barriers facing nurses' compliance regarding prevention pressure ulcer. The study recommended that the managers should review nurses' workload which the findings of this study have shown to be a major barrier in the priority given to the prevention of pressure ulcers.
\end{abstract}

Keywords: Pressure Ulcer, Pressure Ulcer Prevention, Barriers of Prevention Pressure Ulcer

\section{Introduction}

Pressure ulcers are identified worldwide as one of the five most common causes of harm to patients, as well as generally preventable patient safety problem [7]. Throughout recent decades, various efforts have been undertaken to improve pressure ulcer prevention in clinical practice, mostly through implementation of evidence-based guidelines [20], [24], [26]. However, nurses still comply poorly with clinical rules in regards with pressure ulcer prevention. Nurse compliance to guidelines was found to be influenced by several barriers [34], [32]. Lack of knowledge and skills, and negative attitudes in pressure ulcer prevention contributes significantly to the occurrence or worsening of pressure ulcer [23]. Several studies revealed that shortage of supplies for pressure ulcer prevention and shortages of human resource for health, particularly nurses, were the most cited barriers to carrying out appropriate pressure ulcer management [17], [14]. Furthermore, nursing care in relation to pressure ulcers is lacking adequate pressure ulcer documentation, risk assessment, training, and prevention and treatment guidelines [30].

\section{Problem and Significance of Study}

Pressure ulcers are growing in incidence and it is usually the most vulnerable, elderly, and weak of our society who face these complications. High incidences of pressure ulcers in an organization may imply a diminished quality of care [6], [10]. A pilot pressure ulcer prevalence survey conducted across 26 hospitals in Belgium, Italy, Portugal, Sweden and the United Kingdom (UK). The survey include 5947 patients with $1078(18.3 \%)$ having pressure ulcer. By country, the prevalence varied greatly- Italy $(8.3 \%)$, Portugal $(12.5 \%)$, 
Belgium (21.0\%), UK (21.9\%) and Sweden (22.9\%) [31]. One Saudi Arabian study reported acute care pressure ulcer prevalence of $44 \cdot 4 \%$ and incidence of $38.6 \%$ [21]. Pressure ulcer prevention has been a goal of nursing car for a long time and research has been made to identify evidenced based guidelines. Efforts have been made to increase pressure ulcer prevention but pressure ulcer prevalence is still considered to be very high [22]. At the same time, insufficient use of preventative measures in individuals at risk has been repeatedly reported. Independently of the definitions and methods used, studies consistently show that less than half of the patients at risk receive adequate preventative measures as recommended in guidelines [5], [27], [33]. Therefore, the researcher hoped that this study will be valuable. It provides an opportunity to evaluate factors affecting nurses' compliance in preventing pressure ulcer lead to promote best practice in skin care band to enable healthcare managers to design more effective strategies to raise their compliance. Furthermore, there is limited evidence about nurse's practice and barriers to utilize pressure ulcer prevention and treatment care in Saudi Arabia.

\section{Aim of Study}

To assess factors affecting nurses' compliance in preventing pressure ulcer.

\section{Research Questions}

What are the factors affecting nurses' compliance in preventing pressure ulcer?

\section{Methodology}

\subsection{Research Design}

The study's design is a quantitative descriptive correlation, which is type of non-experimental design. This design was selected to assess the correlation between two variables.

\subsection{Settings}

The study was conducted in medical, surgical units and the critical cardiac unit at King Abdulaziz University Hospital, Jeddah city, Kingdome of Saudi Arabia.

\subsection{Sampling}

The Purposive sampling technique was adopted to select a specific group of nurses who were assigned to patients at risk for pressure ulcer. Total studies sample was 113 patients at risk for pressure ulcer and 113 nurses who assigned with same patients. The sample size was determined by using the Steven Thempson formula.

\subsection{Instruments}

To meet the purposes of this research, the researcher was selected three tools.
Tool 1 is structured questionnaire; it was divided into 2 parts. It included (1) demographic data of nurses include gender, age, marital status, years of clinical experience, current level of higher education, and last attendance at training on pressure ulcer. (2) It was a list of 12 barriers facing nurses in prevention of pressure ulcer with the aim of selecting one or more choice, developed and validated by Moore \& Price in 2004, used to measure barriers related to assessing, documenting, and carrying out pressure ulcer prevention practices.

Tool 2 is an observational checklist for nurses, it is likert scale developed by (Mwebaza et al) in 2014 during caring for at risk patients for pressure ulcers to assess a nurse's compliance with pressure ulcer prevention guidelines. It is consisting of three parts: (1) it is related to pressure ulcer screening including two points. (2) It is related to pressure ulcer prevention guidelines, consisting of six points, one of which was about the turning of at-risk patients every two hours up to 4 PM. (3) It is about nurse's documentation consisting of two points.

Tool 3 is Waterlow pressure ulcer risk assessment tool was developed by Waterlow in 2005 and researcher was adapted from KAUH forms. It is likert scale and the primary aim of this tool is to carry out a patient/client risk assessment in relation to pressure ulcer development. It is comprised of eight items: build/weight, visual assessment of the skin, sex, age, continence, mobility, and appetite, and special risk factors, namely tissue malnutrition, neurological deficit, major surgery/trauma, and medication.

\subsection{Validity and Reliability}

A panel of 5 experts (in the fields of statistics, infection control and nursing) revised the content validity of the tool for relevance, clarity, understanding, comprehensiveness, applicability, and ease of implementation. The reliability of the developed tool for the study was tested by using Cronbach's alpha test. The reliability coefficient value was 0.767 for Waterlow pressure ulcer risk assessment tool, 0.685 for Observational checklist to check nurse compliance in preventing the pressure ulcer.

\subsection{Pilot Study}

A pilot study was conducted on 13 nurses to gauge the adequacy and feasibility of the proposed research. An observational checklist and Waterlow assessment tool were used to examine and assess the nurses' performance for 15 to 20 minutes per nurse while providing pressure ulcer care for at risk patients during the day shift.

\subsection{Procedure and Data Collection}

- The procedure of data collection was conducted in the medical, surgical units and critical cardiac unit from $7 \mathrm{am}-$ $4 \mathrm{pm}$ daily.

- The researcher was selected nurses who were assigned to patients identified at-risk for pressure ulcer by using Waterlow risk assessment tool. 
- Verbal consent was obtained from the patients or their relatives along with a written consent form that had been given to the nurses.

- Observation was started at the beginning of the shift for 15 to 20 minutes and then the researcher was followed the nurses every 2 hours by utilizing the observation checklist throughout the remainder of the shift.

- The questionnaire regarding the factors influencing nurse's compliance with pressure ulcer prevention was completed by the nurses who were caring of patients at risk of pressure ulcers.

\subsection{Ethical Consideration}

The agreements for participation of the subjects were taken after aim of the study was explained to them. Before data collection, the nurses and patients were informed about the aim of the study and what would be done with the results. They were given the opportunity to refuse to participate and they could withdraw at any stage of the research. Also, they were assured that the information would remain confidential and use for research purpose only. Official permission was obtained from the unit of Biomedical Ethics of King Abdulaziz University, and the Faculty of Nursing College, after submission of a proposal that was included explanation of the aim, methods, and the procedure of the study; additionally, administrative approval was obtained from the hospital for data collection.

\subsection{Data Analysis}

Each sheet of data collection was manually scored. The Statistical Package for Social Science (SPSS version 19.0) was used to check, enter and analyze the collected data. Data were analyzed using descriptive statistics, which included frequency, percentage, mean, and standard deviation, The TTest was used where there was a significant difference between means of responses of two independent populations, the Paired T-test was used to test whether there was a significant difference between means of responses of two dependent populations, the F-test (Analysis of variance, ANOVA test) was used to test whether there was a significant difference between means of responses of more than two independent populations, and the chi-square test $\left(\chi^{2}\right)$ to measure the associations between two variable statistics. If the p-value is $\leq 0.05$ that indicates that there is a significant relation between the two variables.

\section{Result}

The findings of this study were organized according to the research questions. The aim of this study was to assess the factors that affecting pressure ulcer prevention.

\subsection{Demographic Characteristics of the Nurses $(n=113)$}

Table 1. Frequency Distribution of the Nurses According to Demographic Characteristics $(n=113)$.

\begin{tabular}{llll}
\hline Demographic data & & Frequency & \% \\
\hline \multirow{4}{*}{ Age } & $20-30$ & 30 & 26.5 \\
& $31-40$ & 52 & $46.0^{*}$ \\
Sex & $41-50$ & 29 & 25.7 \\
& $>50$ & 2 & 1.8 \\
& Female & 97 & $85.8^{*}$ \\
Marital status & Male & 16 & 14.2 \\
& Single & 17 & 15.0 \\
& Married & 94 & $83.2^{*}$ \\
Level of qualification & Divorced & 1 & 0.9 \\
& Widow & 1 & 0.9 \\
& Diploma & 58 & $51.3^{*}$ \\
& High diploma & 13 & 11.5 \\
Years of practice & Bachelor & 42 & 37.2 \\
& $1-3$ & 4 & 3.5 \\
Average number of & $4-6$ & 19 & 16.8 \\
patients allocated to a & $7-9$ & 37 & 32.8 \\
nurse & $(1-4)$ & 53 & $46.9^{*}$ \\
& $(1-6)$ & 12 & 10.6 \\
Last attended training & (1-6) & 3 & 2.7 \\
& $>1$ year & 67 & $59.3^{*}$ \\
& $>2$ year & 11 & 27.4 \\
& Never & 8 & 32.8 \\
& & 31 & $50.4^{*}$ \\
& & 57 & 7.1 \\
\hline
\end{tabular}

Table 1 presented the demographic characteristics of the nurses group. As presented, near to the half (46\%) of nurse's age was ranged between 31 and 40 and the majority of the sample was female and married with $(85.8 \%)$ and $(83.2 \%)$ respectively. In relation to the level of qualification for the nurses, over the half $(51.3 \%)$ held a diploma while regarding the years of practice, $(46.9 \%)$ had more than 9 years of practice. As regards the average number of patients allocated to a nurse, more than half of the sample $(59.3 \%)$ had 1 to 6 patients. Also, over the half (50.4\%) of nurses last attended PU training was between 1 and 2 years ago.

\subsection{Nurse's Compliance in Preventing Pressure Ulcer}

Table 2. Frequency Distribution of Nurse's Performance of the Waterlow Scale for All Levels of Risk ( $n=113)$.

\begin{tabular}{|c|c|c|c|c|c|c|c|c|}
\hline \multirow{2}{*}{ Statements } & \multicolumn{2}{|c|}{ Done } & \multicolumn{2}{|c|}{ Not done or not available } & \multirow{2}{*}{$\begin{array}{l}\text { Weighted } \\
\text { Mean }\end{array}$} & \multirow{2}{*}{$\begin{array}{l}\text { Std. } \\
\text { Deviation }\end{array}$} & \multirow{2}{*}{$\begin{array}{l}\text { Overall Response } \\
\text { (in Mean) }\end{array}$} & \multirow{2}{*}{ Priority } \\
\hline & f & $\%$ & f & $\%$ & & & & \\
\hline 1. Statements of Risk. & 71 & 60.68 & 46 & 39.32 & 1.39 & 0.19 & Done & 2 \\
\hline 2. Statements of high Risk. & 116 & 56.04 & 91 & 43.96 & 1.44 & 0.11 & Done & 1 \\
\hline 3. Statements of very high Risk. & 789 & 70.32 & 333 & 29.68 & 1.30 & 0.15 & Done & 3 \\
\hline Total & 976 & $67.50 *$ & 470 & 32.50 & 1.36 & 0.17 & Done & \\
\hline
\end{tabular}

*A numbers are not mutually exclusive 
Table 2 described the frequency distribution of nurses 'performance of the Waterlow scale for all levels of risk. Two-thirds of nurses $(67.50 \%)$ were done all that is needed by the Waterlow scale while more than one third (32.50) were not done all that needed by Waterlow scale.

Table 3. Frequency Distribution of Nurse's Compliance in Preventing Pressure Ulcers (n=113).

\begin{tabular}{|c|c|c|c|c|c|c|}
\hline \multirow{2}{*}{ Statements } & \multicolumn{2}{|c|}{ Done } & \multicolumn{2}{|c|}{ Not done or Incorrectly done } & \multirow{2}{*}{$\begin{array}{l}\text { Weighted } \\
\text { Mean }\end{array}$} & \multirow{2}{*}{$\begin{array}{l}\text { Std. } \\
\text { Deviation }\end{array}$} \\
\hline & f & $\%$ & f & $\%$ & & \\
\hline 1- Following policy by using a risk assessment tool (Waterlow scale). & 28 & $24.8^{*}$ & 85 & 75.2 & 1.75 & 0.43 \\
\hline 2- Provide skin inspection of high risk patient for pressure ulcer. & 19 & 16.8 & 94 & 83.2 & 1.83 & 0.38 \\
\hline $\begin{array}{l}\text { a- Conducting continuous assessment of areas at risk of developing pressure } \\
\text { ulcer. }\end{array}$ & 13 & $11.5^{*}$ & 100 & 88.5 & 1.88 & 0.32 \\
\hline b.1- 8 A.M. & 86 & 76.1 & 27 & 23.9 & 1.24 & 0.43 \\
\hline b.2 - 10 A.M. & 82 & 72.6 & 31 & 27.4 & 1.27 & 0.45 \\
\hline b.3 - 12 P.M. & 86 & 76.1 & 27 & 23.9 & 1.24 & 0.43 \\
\hline b.4 - 2 P.M. & 83 & 73.5 & 30 & 26.5 & 1.27 & 0.44 \\
\hline b.5 - 4 P.M. & 89 & 78.8 & 24 & 21.2 & 1.21 & 0.41 \\
\hline c. Controlling moisture on the skin of patients who are at risk. & 93 & 82.3 & 20 & 17.7 & 1.18 & 0.38 \\
\hline d. Involving other health workers in prevention of pressure ulcer. & 50 & 44.2 & 63 & 55.8 & 1.56 & 0.50 \\
\hline 2- Availability of pressure ulcer devices (Mattresses, Cushions, others). & 21 & 18.6 & 92 & 81.4 & 1.81 & 0.39 \\
\hline 3- Using preventive pressure ulcer devices (Mattresses, Cushions, others). & 23 & $20.4^{*}$ & 90 & 79.6 & 1.80 & 0.40 \\
\hline c1. Completing the pressure ulcer risk assessment tool directly. & 109 & 96.5 & 4 & 3.5 & 1.04 & 0.19 \\
\hline c2. Completing the documentation in the file. & 112 & $99.1^{*}$ & 1 & 0.9 & 1.01 & 0.09 \\
\hline Total & 894 & $56.51^{*}$ & 688 & 43.49 & 1.43 & 0.14 \\
\hline
\end{tabular}

*A numbers are not mutually exclusive

Table 3 represented frequency distribution of nurse's compliance in preventing pressure ulcer. Over than half of the studied sample $(56.51 \%)$ was performing most of the statements while more than one third $(43.49 \%)$ was not complied. The majority of nurses $(99 \%)$ were completed the documentation in the file however only minority of nurses $(11.5 \%)$ were conducted continue assessment of areas at risk of developing pressure ulcer.

\subsection{Barriers Facing Nurses in Preventing Pressure Ulcer}

Table 4. Frequency Distribution of Barriers Facing the Staff Nurses in Preventing Pressure Ulcers $(n=113)$.

\begin{tabular}{|c|c|c|c|}
\hline Barriers facing staff in preventing pressure ulcers. & Frequency & $\%$ & Rank \\
\hline 1. Poor access to literature about pressure ulcer. & 12 & $10.6^{*}$ & 5 \\
\hline 2. Heavy workload / staff shortage. & 107 & $94.7^{*}$ & 1 \\
\hline 3. Lack of universal guidelines for prevention. & 8 & 7.1 & 6 \\
\hline 4. Lack of in-service training about pressure ulcer. & 7 & 6.2 & 7 \\
\hline 5. Uncooperative patients. & 78 & $69.0^{*}$ & 2 \\
\hline 6. Presence of priorities other than pressure ulcer. & 30 & $26.5^{*}$ & 4 \\
\hline 7. Shortage of pressure-relieving devices. & 46 & $40.7^{*}$ & 3 \\
\hline 8. Problem with assessment tool. & 0 & 0.0 & 12 \\
\hline 9. Inadequate knowledge of pressure ulcer. & 6 & 5.3 & 8 \\
\hline 10. I do not have any challenges. & 2 & 1.8 & 9 \\
\hline 11. Forgot. & 2 & 1.8 & 9 \\
\hline 12. Other barriers. & 2 & 1.8 & 9 \\
\hline
\end{tabular}

*A numbers are not mutually exclusive

Table 4 showed that the frequency distribution of each barrier facing the staff nurses in preventing pressure ulcer. There were four important barriers facing the staff nurses in preventing pressure ulcers. The majority of the nurses (94.7\%) were mentioned heavy workload / staff shortages as barrier in preventing pressure ulcer, more than two-third of nurses $(69.0 \%)$ were selected uncooperative patients as a second barrier; while more than one third of nurses $(40.7 \%)$ were described a shortage of pressure-relieving devices as a third barrier, finally minority of nurses (26.5\%) were considered presence of priorities other than pressure ulcer as the fourth barrier. 


\subsection{The Relation Between the Variables}

Table 5. Relation Between Nursing Performance (Waterlow) and Barriers Facing Staff in Preventing PU ( $n=113)$.

\begin{tabular}{|c|c|c|c|c|c|}
\hline \multirow{3}{*}{$\begin{array}{l}\text { Barriers facing staff in } \\
\text { preventing P.U. }\end{array}$} & \multicolumn{2}{|c|}{ Nursing care to prevent pressure ulcer (Waterlow) } & \multirow{3}{*}{$x^{2}$} & \multirow{3}{*}{ d.f } & \multirow{3}{*}{$\begin{array}{l}\text { Sig. } \\
\text { (p-value) }\end{array}$} \\
\hline & Done & Not done & & & \\
\hline & f (\%) & f (\%) & & & \\
\hline 1. Poor access to literature about pressure ulcer. & $8(7.1)$ & $4(3.5)$ & 1.646 & 1 & 0.200 \\
\hline \multirow{2}{*}{ 2. Heavy workload / staff shortage } & $88(77.9)$ & $19(16.8)$ & \multirow{2}{*}{3.767} & \multirow{2}{*}{1} & \multirow{2}{*}{$0.050^{*}$} \\
\hline & $3(2.7)$ & $3(2.7)$ & & & \\
\hline \multirow{2}{*}{ 3. Lack of universal guidelines for prevention. } & $5(4.4)$ & $3(2.7)$ & \multirow{2}{*}{1.785} & \multirow{2}{*}{1} & \multirow{2}{*}{0.182} \\
\hline & $86(76.1)$ & $19(16.8)$ & & & \\
\hline 4. Lack of in-service training about pressure ulcer. & $86(76.1)$ & $20(17.7)$ & 0.394 & 1 & 0.530 \\
\hline \multirow{2}{*}{ 5. Uncooperative patients. } & $65(57.5)$ & $13(11.5)$ & \multirow{2}{*}{1.261} & \multirow{2}{*}{1} & \multirow{2}{*}{0.261} \\
\hline & $26(23.0)$ & $9(8.0)$ & & & \\
\hline \multirow{2}{*}{ 6. Presence of priorities other than pressure ulcer. } & $21(18.6)$ & $9(8.0)$ & \multirow{2}{*}{2.889} & \multirow{2}{*}{1} & \multirow{2}{*}{0.089} \\
\hline & $70(61.9)$ & $13(11.5)$ & & & \\
\hline \multirow{2}{*}{ 7. Shortage of pressure-relieving devices. } & $38(33.6)$ & $8(7.1)$ & \multirow{2}{*}{0.214} & \multirow{2}{*}{1} & \multirow{2}{*}{0.644} \\
\hline & $53(46.9)$ & $14(12.4)$ & & & \\
\hline 8 Problem with assessment tool & - & - & - & - & - \\
\hline 9 Inadequate knowledge of pressure ulcer & $3(2.7)$ & $3(2.7)$ & 3.767 & 1 & $0050 *$ \\
\hline 9. madequate knowiedge or pressure uicer. & $88(77.9)$ & $19(16.8)$ & & & 0.050 \\
\hline 10. Do not have any challenges & $2(1.8)$ & $0(0.0)$ & 0.492 & 1 & 0.483 \\
\hline & $89(78.8)$ & $22(19.5)$ & & & \\
\hline 11. Forget to record patients' assessments. & $0(0.0)$ & $2(1.8)$ & 8.422 & 1 & $0.004^{*}$ \\
\hline & $91(80.5)$ & $20(17.7)$ & & & \\
\hline 12. Other barriers & $2(1.8)$ & $0(0.0)$ & 0.492 & 1 & 0.483 \\
\hline & $89(78.8)$ & $22(19.5)$ & & & \\
\hline
\end{tabular}

* Statistically significant at $\mathrm{P} \leq 0.05$

Table 5 described the relation between nursing performance (Waterlow) and barriers facing staff in preventing pressure ulcer, there were significant relation with heavy workload / staff shortages, inadequate knowledge of pressure ulcer and forgetting to record patients' assessment, $\mathrm{P}=(0.05),(0.05)$, $(0.00)$ respectively. That is mean there is significant relationship between nursing performance (Waterlow) and barrier facing nurses in preventing pressure ulcer.

Table 6. Relation between the Nurse Compliance in Preventing Pressure Ulcers and Barriers Facing Staff in Preventing P.U ( $n=113$ ).

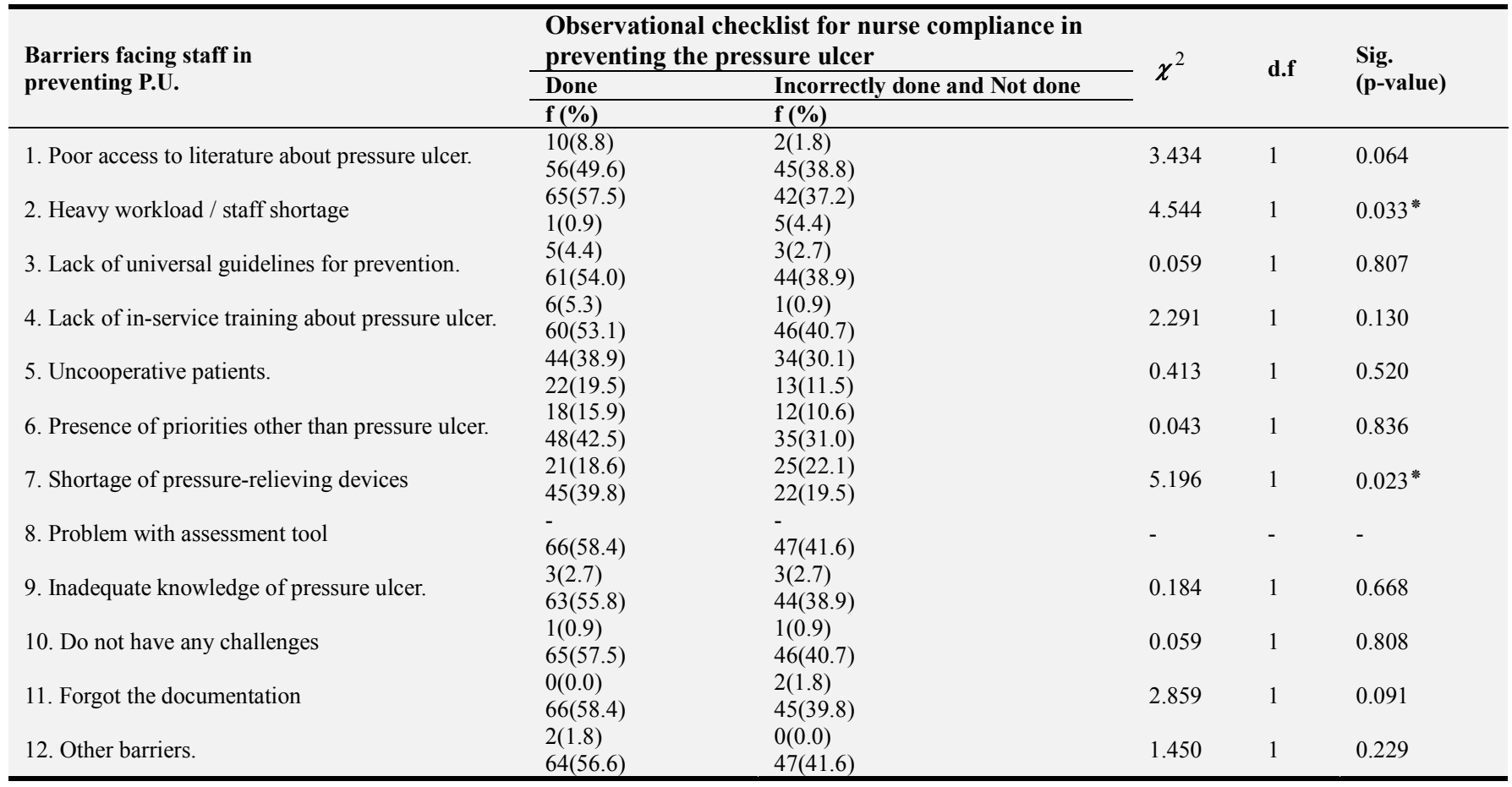

* Statistically significant at $\mathrm{P} \leq 0.05$ 
Table 6 showed that the relation between nursing compliance (observational checklist) and barriers facing staff in preventing pressure ulcer, there were a significant relation with heavy workload / staff shortage $(\mathrm{P}=0.03)$ and Shortage of pressure-relieving devices $(\mathrm{P}=0.02)$, which mean there is significant relationship between these barriers and nursing compliance in preventing pressure ulcer.

\subsection{Correlation Between Factors}

Table 7. Correlation between Waterlow Risk Assessment Tool and Observational Checklist $(N=113)$.

\begin{tabular}{llll}
\hline Factor & & $\begin{array}{l}\text { Waterlow risk } \\
\text { assessment tool }\end{array}$ & $\begin{array}{l}\text { Observational } \\
\text { Checklist }\end{array}$ \\
\hline $\begin{array}{l}\text { Waterlow } \\
\text { protocol }\end{array}$ & $\begin{array}{l}\text { Pearson correlation } \\
\text { Sig (p-value). }\end{array}$ & 1 & \\
$\begin{array}{l}\text { Observational } \\
\text { protocol }\end{array}$ & $\begin{array}{l}\text { Pearson correlation } \\
\text { Sig (p-value). }\end{array}$ & $0.249^{* *}$ & \\
\hline
\end{tabular}

** Correlation is significant at the 0.01 level (2-tailed)

Table 7 shown that there is a highly significant correlation is between nurse's performance of pressure ulcer risk assessment and the nursing compliance in preventing pressure ulcer by observational checklist.

\section{Discussion}

The purpose of the discussion is to interpret and describe the significance of your findings in light of what was already known about the research problem being investigated, and to explain any new understanding or insights about the problem after you've taken the findings into consideration. The discussion will always connect to the introduction by way of the research questions or hypotheses you posed and the literature you reviewed [3].

\section{Study Findings:}

Socio-demographic characteristics of the nurses

Regarding the demographic data, in table 1 showed that most participants (46\%) were aged from 31-40 years, with $85.8 \%$ female and $83.2 \%$ married. In relation to their level of qualification, $51.3 \%$ had diplomas in nursing and $46.9 \%$ had more than 9 years of experience. Over the half of the sample (50.4\%) last attended training on PU between 1-2 years ago. Also, $59.3 \%$ of nurses had allocated to average number of 1 to 6 patients.

\section{Nurse's compliance in preventing pressure ulcer}

In regard to nurse's performance of the Waterlow scale for all levels of risk in table 2 , the findings showed that more than $2 / 3$ of the nurses' responses $(67.50 \%)$ had complied with the requirements of the Waterlow scale. Therefore, the finding of this study disagrees with Vanderwee et al. (2007) which revealed that 18 out of 78 nurses had no official training on pressure ulcer prevention and that 43 of the nurses admitted to not knowing how to use risk assessment [31].

Regarding the nurse's compliance in pressure ulcer prevention processes in table 3 , revealed that the overall response for the most of statements is "Done" (56.51\%), which means that the nurses had completed their assignments. In this study only $11.5 \%$ of nurses conducting continuous assessment of area at risk of developing pressure ulcer while $20.4 \%$ of the nurses were using a preventive pressure ulcer device. The findings also revealed that not all the nurses were using a pressure ulcer risk assessment tool $(24.8 \%)$. Despite this fact, $99.1 \%$ of the nurses still completed the related documentation which is clearly an issue. According to Gefen (2008) only $12 \%$ of nurses in selected United States hospitals repositioning every 2 hours their patients [9]. In addition, in Belgium, Paquay. et al (2008) found where $69.2 \%$ of all at risk patients had pressure relieving devices [18]. In Ireland, only $75 \%$ of them could identify which tool was being used, despite the fact that $95 \%$ of nurses were using an assessment tool [15]. This practice might not be directly concentrating on pressure ulcers alone, but it is obvious that is a good prevention measure [12], [29].

Barriers facing nurses in preventing pressure ulcer

In relation to barriers facing staff in preventing pressure ulcer, it was found in table 4 that $94.7 \%$ perceived heavy workloads to be causative and were related to shortage of staff, patients were also considered a barrier when they were identified as being uncooperative $(69.0 \%)$ and shortage of pressure relieving devices was also mentioned by (40.7\%). Other barriers were poor access to pressure ulcer literature $(10.6 \%)$ and inadequate coverage about pressure ulcers during training. The researcher noticed that the most important barrier facing nurses is heavy workload. In spite of existence of strict guidelines regarding pressure ulcer, nurses did not have enough time to apply it carefully.

These findings were supported by the results of Jordan et al. (2011), who found that the main barriers to the completion of nursing documentation of PU care plans were a lack of time and staff [13]. Also, according to Mwebaza et al. (2014), lack of supplies for pressure ulcer management and prevention, and a shortage of human healthcare resources, particularly nurses were potential and actual barriers to implementing pressure ulcer prevention and management. Heavy workloads related to shortage of staff (94.6\%) and shortage of pressure relieving devices were also mentioned in the same study. The similarities continued to be seen with patients being also considered as a barrier when they were identified as uncooperative $(62.5 \%)$. Poor access to pressure ulcer literature $(37.5 \%)$ and inadequate coverage about pressure ulcers during training $(23.2 \%)$ considered as barriers also [17]. Pressure ulcer prevention is an interdisciplinary issue and thus needs team work to contribute to successful care and multidisciplinary efforts. Staff shortages are created an additional problem, which results in work overloads for staff at the clinical level. Certain parts of PU prevention, for example, repositioning, are hard to complete unaided. The researcher believes that if staff deficiencies proceed, with the stress caused during busy and overloaded clinical shifts, it will be expected that PU prevention will become a lower priority. 
Relation between nursing performance (Waterlow) and barriers facing staff in preventing $P U$

Regarding the Relation between nursing care tools to assessing pressure ulcer (Waterlow) and barriers encountered by staff in preventing pressure ulcers, in table 5 showed that there were significant relation with workload/shortage staff, inadequate knowledge of pressure ulceration and the nurses forgetting to complete patient's records. The researcher observed that the nurses completed the documentation and risk assessment scales without checking each item with their patients thereby indicating some deficiencies in the nurse's knowledge regarding the risk assessment tools for the prevention of pressure ulcer. In agreement with these findings, Jankowski \& Nadzam (2011) stated that as a lack of nurse's knowledge is still seen as one of the principal causes for pressure ulcer development, pressure ulcers are increasingly seen as a quality of care indicator [12]. Also, it was noted by Adejumo (2011) that most organizations/hospitals do not recognize seminars and symposiums which are related to pressure ulcer prevention or use of risk assessment scales; hence this affects the knowledge level of nurses on hence affecting nurses' levels of knowledge on the topics [1]

Ayello (2007) identified a shortage of staff and lack of time as factors affecting nurses' use of risk assessment scales respectively. This can influence the use of risk assessment scale because patient - nurse ratios are 10:1 in most healthcare settings; while nurses' levels of stress can create a negative miscalculation of patients at risk [4]. In addition, the researcher noticed that workload leads nurses to forget to complete the risk assessment tool, which in this study is considered a barrier that affects the process of the Waterlow scale. Higher staffing levels were associated with decreased incidence of PUs [19].

Relation between the nurse compliance in preventing pressure ulcers and barriers facing staff in preventing P.U

The relation between nurses' compliance in prevention of pressure ulcer and barriers facing staff in table 6 represented that significant relationship with two variables only: the heavy workload/staff shortages and the shortage of pressurerelieving devices. During observation researcher discovered there is a shortage in the amount of the device which lead the nurses to forget using it when it is available.

This result concurs with Hadley \& Roques (2007) who reported that a moderate standard of practice among nurses may be associated with certain factors such as the shortage of nursing staff and the limited time for patient care [11]. Several studies showed that a lack of PU-prevention equipment is an obstacle to this practice [14], [25]. Described as being related to the quality of care, nurse staffing levels are an essential factor [2].

Correlation between factors

In table 7 , the researcher found significant correlation between nursing compliance in preventing of pressure ulcer (observational checklist) and the performance of the risk assessment tool (Waterlow). These findings supported a previous study, conducted by Tescher et al. (2012), by using a risk assessment tools' subscales, prevention could be more focused on specific patient needs [28]. Also according to Fernandes and Caliri (2008) explained that the use of risk assessment instruments for PU development, similar to the Braden scale is to recognize patients at risk and related risk factors, helping nurses to make decisions on planning subsequent prevention measures for each patient to adopt. These scales and their uses should be a priority in nursing education and professional development programs [8].

\section{Conclusion}

This correlation research sought to have a positive impact on the preventive care provided by nurses to patients at risk for pressure ulcers by exploring evidence-based research concerning the effects of the factors affecting nursing compliance with the protocols for preventing pressure ulcers. Pressure ulcer prevention is an interdisciplinary problem. Thus, it needs multidisciplinary efforts and team work to contribute to successful care. Inadequate facilities and equipments, dissatisfaction with staff shortage were found to be barriers facing nurses in following evidence based practice of pressure ulcer prevention. If staff shortages continue, with the stress caused during the busy and overloaded clinical shifts, it will be no surprise if pressure prevention becomes less of a priority. In-service training, upgrading courses and ensuring availability of the necessary facilities and equipments are some of the important steps to improve nurses' knowledge and practice regarding to prevention of pressure ulcer.

\section{Recommendations}

1. The nurse manager should perform interviews with the nurses prior to the planning of the PU prevention strategies to determine potential barriers to their successful implementation.

2. The managers should review nurses' workload which the findings of this study have shown to be a major barrier in the priority given to the prevention of pressure ulcer.

3. Interpersonal communication between registered nurses and first line managers, based on quality measurements, was the key factor for the improvement of nursing practice.

4. Extended future research to cover more facilities in the Jeddah region in order to increase the variety of the sample or to replicate the study in various geographic areas using a larger probability sample.

\section{References}

[1] Adejumo, P. (2011). Nurses' perception of activities at preventing pressure sore among selected patients at the University College hospital, Ibadan. West Afr. J. Nurs. 21(2): 90-98. Advanced Nursing 54, 94-10. 
[2] Aiken, LH., Sloane, DM., Bruyneel, L., Van den Heede, K., Griffiths, P., Busse R, Diomidous M, Kinnunen J, Kozka M, Lesaffre E, McHugh Moreno-Casbas, MT., Rafferty, A. M., Schwendimann, R., Scott, P. A., Tishelman C, van Achterberg $\mathrm{T} \&$ Sermeus W (2014). Nurse staffing and education and hospital mortality in nine European countries: a retrospective observational study. Lancet 383, 1824.

[3] Annesley Thomas M. (2010). "The Discussion Section: Your Closing Argument.” Clinical Chemistry 56: 1671-1674.

[4] Ayello, E. (2007). How and why to do pressure ulcer risk assessment. Adv. Skin Wound Care 15(3): 125-320.

[5] Bredesen, I. M., Bjøro, K., Gunningberg, L., and Hofoss, D. (2015). The prevalence, prevention and multilevel variance of pressure ulcers in Norwegian hospitals: a cross-sectional study. Int. J. Nurs. Stud.; 52: 149-156

[6] Elliot R, McKinley S, Fox V. (2008). Quality improvement program to reduce the prevalence of pressure ulcers in an intensive care unit. Am J Crit Care; 17: 4.

[7] European Pressure Ulcer Advisory Panel \& National Pressure Ulcer Advisory Panel (2009). Prevention and treatment of pressure ulcers: quick reference guide. National Pressure Ulcer Advisory Panel, Washington DC.

[8] Fernandes, L. M., Caliri, M. H. L. (2008). Uso da escala de Braden e de Glasgow para identificação do risco para úlceras de pressão em pacientes internados em centro de terapia intensiva. Rev. Latino-Am. Enfermagem. 16(6): 973-8.

[9] Gefen, A. (2008). "How much time does it take to get a pressure ulcer? Integrated evidence from human, animal, and in vitro studies," Ostomy Wound Management, vol. 54, no. 10

[10] Gunningberg, L. and N. Stotts (2008). "Tracking quality over time: what do pressure ulcer data show?" International Journal of Quality in Health Care 20(4): 246-253.

[11] Hadley, M. B., Roques, A. (2007). Nursing in Bangladesh: Rhetoric and reality. Social Science and Medicine. 64: 115365. PMid: 16884841 http://dx.doi.org/10.1016/j.socscim ed.2006.06.032.

[12] Jankowski, M. I and Nadzam, M. D. (2011): Identifying gaps, barriers, and solutions in implementing pressure ulcer prevention programs, The joint Commission Journal on Quality and Patient Safety,(37)(6) 154-60.

[13] Jordan O'Brien JA, Cowman S. (2011). An exploration of nursing documentation of pressure ulcer care in an acute setting in Ireland. J Wound Care. 20(5): 197-205.

[14] Källman U, Suserud B. (2009). Knowledge, attitudes and practice among nursing staff concerning pressure ulcer prevention and treatment-a survey in a Swedish healthcare setting. Scand J Caring Sci.; 23(2): 334-41. doi: 10.1111/j.1471-6712.2008.00627.x.

[15] MOORE, Z. \& COWMAN, S. (2012). Pressure ulcer prevalence and prevention practices in care of the older person in the Republic of Ireland. J Clin Nurs, 21, 362-71.

[16] Moore, Z., Price, P. (2004): Nurses' attitudes, behaviors and perceived barriers towards pressure ulcer prevention. J Clin Nurs, 13: 942-952.

[17] Mwebaza I, Katende G, Groves S, Nankumbi J. (2014)Nurses'
Knowledge, Practices, and Barriers in Care of Patients with Pressure Ulcers in a Ugandan Teaching Hospital. Nursing Research and Practice.; 2014: 973602. doi: 10.1155/2014/973602.

[18] Paquay, L., Wouters, R., Defloor, T., Buntinx, F., Debaillie, R. and Geys, L. (2008). "Adherence to pressure ulcer prevention guidelines in home care: a survey of current practice," Journal of Clinical Nursing, vol. 17, no. 5, pp. 627-636.

[19] Park, S. H., Boyle, D. K., Bergquist-Beringer, S., Staggs, V. S. \& Dunton, N. E. (2014). Concurrent and lagged effects of registered nurse turnover and staffing on unit-acquired pressure ulcers. Health Serv Res 49, 1205-1225. patients in selected hospitals at Mangalore, Published master thesis in Medical - Surgical Nursing, Athena College of Nursing, Failnir Road: p. 3.

[20] Niederhauser, A., Van Deusen Lukas, C., Parker, V., Ayello, E. A., Zulkowski, K., and Berlowitz, D. (2012). Comprehensive programs for preventing pressure ulcers: a review of the literature. Adv. Skin Wound Care.25: 167-188

[21] Saleh M (2007). The impact of pressure ulcer risk assessment on patient outcomes among hospitalised patients at Riyadh Military Hospital - Saudi Arabia. Leicester: De Montfort University.

[22] Shahin, E. S. M., Dassen, T. and Halfens, R. J. G. (2008). Pressure ulcer prevalence and incidence in intensive care patients: a literature review. Nursing in Critical Care. 13(2): 71-79. PMid: 18289185 http://dx.doi.org/10.1111/j.14785153.2007.00249.x.

[23] Smith D, Waugh S. (2009). Research study: an assessment of registered nurses' knowledge of pressure ulcers prevention and treatment. Kansas Nurs. 84(1): 3-5.

[24] Soban et al., (2011) Soban, L. M., Hempel, S., Munjas, B. A., Miles, J., and Rubenstein, L. V. Preventing pressure ulcers in hospitals: a systematic review of nurse-focused quality improvement interventions. Jt. Comm. J. Qual. Patient. Saf.; 37: $245-252$.

[25] Strand, T., Lindgren, M. (2010). Knowledge, attitudes and barriers towards prevention of pressure ulcers in intensive care units: A descriptive cross-sectional study. Intensive Crit Care Nurs. 26: 335-342.

[26] Sullivan, N. and Schoelles, K. M. (2013). Preventing infacility pressure ulcers as a patient safety strategy: a systematic review. Ann. Intern. Med.; 158: 410-416.

[27] Sving, E., Idvall, E., Högberg, H., and Gunningberg, L. (2014). Factors contributing to evidence-based pressure ulcer prevention. A cross-sectional study. Int. J. Nurs. Stud.; 51: $717-725$.

[28] Tescher, A. N., Branda, M. E., Byrne, T. J. \& Naessens, J. M. (2012). All at-risk patients are not created equal: analysis of Braden pressure ulcer risk scores to identify specific risks. J Wound Ostomy Continence Nurs 39, 282-291.

[29] Thayer, D. (2013), "Closing the evidence-based gap in skin care.http://www.o-wm.com/content/closing-evidence-basedgap-skin-care.

[30] Tubaishat, A., D. Anthony, and M. Saleh (2011). Pressure ulcers in Jordan: A point prevalence study. Journal of Tissue Viability, 20(1), 14-19. PMid: 20880710 http://dx.doi.org/10.1016/j.jtv.2010.08.001 
[31] Vanderwee, K., Grypdonck, M. \& Defloor, T. (2007b). Nonblanchable erythema as an indicator for the need for pressure ulcer prevention: a randomized-controlled trial. Journal of Clinical Nursing 16, 325-335.

[32] Van Gaal BG, Schoonhoven L, Vloet LC, Mintjes JA, Borm GF, Koopmans RT, van Achterberg T. (2010): The effect of the SAFE or SORRY? programme on patient safety knowledge of nurses in hospitals and nursing homes: a cluster randomized trial. Int J Nurs Stud., 47 (9): 1117-1125. 10.1016/j.ijnurstu.02.001.

[33] Van Gaal, B. G., Schoonhoven, L., Mintjes-de Groot, J. A.,
Defloor, T., Habets, H., Voss, A., van Achterberg, T., and Koopmans, R. T. (2014). Concurrent incidence of adverse events in hospitals and nursing homes. J. Nurs. Scholarsh.; 46: 187-198.

[34] Wann-Hansson, C., Hagell, P. \&Willman, A. (2008). Risk factors and prevention among patients with hospital-acquired and pre- existing pressure ulcers in an acute care hospital. Journal of Clinical Nursing, 17, 1718-1727. doi: 10.1111/j.1365-2702.2008.02286.x.

[35] Waterlow, J. (2005). Pressure Ulcer Prevention Manual. Taunton: Waterlow. 